\title{
Development of System-level Performance Measures for Evaluation of Models of Care for Inflammatory Arthritis in Canada
}

\author{
Claire E.H. Barber, Deborah A. Marshall, Dianne P. Mosher, Pooneh Akhavan, Lori Tucker, \\ Kristin Houghton, Michelle Batthish, Deborah M. Levy, Heinrike Schmeling, Janet Ellsworth, \\ Heidi Tibollo, Sean Grant, Dmitry Khodyakov, Diane Lacaille, and the Arthritis Alliance of \\ Canada Performance Measurement Development Panel
}

\begin{abstract}
Objective. To develop system-level performance measures for evaluating the care of patients with inflammatory arthritis (IA), including rheumatoid arthritis (RA), psoriatic arthritis, ankylosing spondylitis, and juvenile idiopathic arthritis.

Methods. This study involved several methodological phases. Over multiple rounds, various participants were asked to help define a set of candidate measurement themes. A systematic search was conducted of existing guidelines and measures. A set of 6 performance measures was defined and presented to 50 people, including patients with IA, rheumatologists, allied health professionals, and researchers using a 3-round, online, modified Delphi process. Participants rated the validity, feasibility, relevance, and likelihood of use of the measures. Measures with median ratings $\geq 7$ for validity and relevance were included in the final set.

Results. Six performance measures were developed evaluating the following aspects of care, with each measure being applied separately for each type of IA except where specified: waiting times for rheumatology consultation for patients with new onset IA, percentage of patients with IA seen by a rheumatologist, percentage of patients with IA seen in yearly followup by a rheumatologist, percentage of patients with RA treated with a disease-modifying antirheumatic drug (DMARD), time to DMARD therapy in RA, and number of rheumatologists per capita.

Conclusion. The first set of system-level performance measures for IA care in Canada has been developed with broad input. The measures focus on timely access to care and initiation of appropriate treatment for patients with IA, and are likely to be of interest to other arthritis care systems internationally. (First Release January 15 2016; J Rheumatol 2016;43:530-40; doi:10.3899/jrheum.150839)
\end{abstract}

Key Indexing Terms:

QUALITY INDICATORS RHEUMATOID ARTHRITIS PSORIATIC ARTHRITIS

JUVENILE IDIOPATHIC ARTHRITIS

ANK YLOSING SPONDYLITIS

\footnotetext{
From the Division of Rheumatology, Department of Medicine, and Section of Rheumatology, Department of Pediatrics, University of Calgary; Department of Community Health Sciences, Canada Research Chair in Health Systems, Calgary; Division of Pediatric Rheumatology, University of Alberta/Stollery Children's Hospital, Edmonton, Alberta; Division of Rheumatology, Department of Medicine, University of Toronto, Mount Sinai Hospital; Hospital for Sick Children, University of Toronto, Toronto; Division of Rheumatology, McMaster Children's Hospital, Department of Pediatrics, McMaster University, Hamilton, Ontario; Division of Rheumatology, Department of Pediatrics, University of British Columbia, BC Children's Hospital; Division of Rheumatology, Department of Medicine, University of British Columbia, Vancouver; Arthritis Research Centre of Canada, Richmond, British Columbia, Canada; Doctor Evidence LLC; the RAND Corporation, Santa Monica, California, USA.

Funding from a Canadian Institutes for Health Research Planning Grants 2013-10-15 (Funding reference number is 218913). Additional funding and in-kind resources provided by the Arthritis Alliance of Canada $(A A C)$. Dr. Lacaille holds the Mary Pack Chair in Arthritis Research from the University of British Columbia and The Arthritis Society of Canada. C.E. Barber, MD, FRCPC, PhD Candidate, Assistant Professor, Division of Rheumatology, Department of Medicine, University of Calgary; D.A. Marshall, BSc, MHSA, PhD, Associate Professor, Department of
}

\begin{abstract}
Community Health Sciences, Canada Research Chair in Health Systems, and Services Arthur JE Child Chair in Rheumatology Research, University of Calgary; D.P. Mosher, MD, FRCPC, Chief, Division of Rheumatology, Department of Medicine, University of Calgary; P. Akhavan, MD, MSc, FRCPC, Division of Rheumatology, Department of Medicine, University of Toronto, Mount Sinai Hospital; L. Tucker, MD, FRCPC, Clinical Associate Professor, Division of Rheumatology, Department of Pediatrics, University of British Columbia; K. Houghton, MD, FRCPC, Clinical Associate Professor, Division of Rheumatology, Department of Pediatrics, University of British Columbia, BC Children's Hospital; M. Batthish, MSc, MD, FRCPC, Staff Physician, Division of Rheumatology, McMaster Children's Hospital, Assistant Professor, Department of Pediatrics, McMaster University; D.M. Levy, MD, MS, FRCPC, Staff Rheumatologist, Hospital for Sick Children, Assistant Professor of Pediatrics, University of Toronto; H. Schmeling, MD, PhD, Assistant Professor, Clinician Scientist, Section of Rheumatology, Department of Pediatrics, University of Calgary; J. Ellsworth, MD, FRCPC, Professor and Head, Division of Pediatric Rheumatology, University of Alberta/Stollery Children's Hospital; H. Tibollo, MLS, BSN, Medical librarian, Doctor Evidence LLC; S. Grant, DPhil, Associate Behavioural/Social Scientist, the RAND Corporation; D. Khodyakov, PhD, MA, Social/Behavioral Scientist, the RAND Corporation; D. Lacaille, MD, FRCPC, MHSc, Professor, Division of Rheumatology, Department of Medicine, University of British
\end{abstract}


Columbia, and Senior Scientist, Arthritis Research Centre of Canada. Address correspondence to Dr. C.E. Barber, Division of Rheumatology, University of Calgary, HRIC Room 3AA20, 3280 Hospital Dr. NW, Calgary, Alberta T2N 4Z6, Canada.E-mail: cehbarbe@ucalgary.ca Full Release Article. For details see Reprints/Permissions at jrheum.org Accepted for publication October 31, 2015.

It is estimated that over a million Canadians have inflammatory arthritis (IA), including rheumatoid arthritis (RA), ankylosing spondylitis (AS), juvenile idiopathic arthritis (JIA), and psoriatic arthritis (PsA) ${ }^{1}$. Early detection and treatment improves outcomes in $\mathrm{RA}^{2,3}$ and evidence is emerging for other types of $\mathrm{IA}^{4,5,6}$. Rheumatologists are the medical specialists primarily responsible for diagnosing and treating people with IA. Unfortunately, the number of rheumatologists in many regions may be inadequate to ensure timely access to care for patients ${ }^{7,8}$. The rising burden of IA, a projected shortage of rheumatologists $7,8,9$, and recognized gaps in current care ${ }^{10}$ prompted the Arthritis Alliance of Canada (AAC) to consider new models of care delivery to optimize access, treatment, and patient outcomes in $\mathrm{IA}^{1}$. A model of care is a strategy that describes an optimal, evidence-based approach to care delivery with an emphasis on what resources and processes are needed to deliver high-quality care at a community level ${ }^{11}$.

A critical component of model of care implementation is evaluation. The objective of our study was to develop system-level measures to evaluate a model of care as they are reported at a regional, provincial, or national level in contrast with patient-provider level measures, which identify and evaluate individual physician performance. The measures focus on measuring access to care and treatment provided by a model of care and are for research and quality improvement. Although the measures have been developed in a Canadian context, the measures are likely highly relevant to other arthritis settings.

\section{MATERIALS AND METHODS}

The AAC has over 36 member organizations from across Canada ${ }^{12}$ and provides a central focus for national arthritis-related initiatives, including this project.

The performance measures were developed over 4 phases (Figure 1).

Phase 1: Establishing measurement priorities. A sequential process was used to establish measurement priorities (Figure 1; Supplementary Appendix, available online at jrheum.org). First, a literature review of published measures and clinical practice guidelines for IA care was conducted to identify possible measurement themes. The results of this review informed a draft set of measurement themes that was mapped onto the 6 dimensions of quality of care (effectiveness, accessibility, safety, efficiency, acceptability, and appropriateness ${ }^{13}$; see Supplementary Figure 1 and Supplementary Figure 2 for search strategy and results, available online at jrheum.org). The measurement themes were reviewed during a series of meetings with healthcare workers and patients both in person and by teleconference to first expand and then refine the themes, considering feasibility and priorities. Thirteen out of 19 (68\%) AAC members, including rheumatologists and health services researchers with expertise in models of care and/or performance measurement, completed an anonymous online poll to select the most feasible, valid, and relevant themes, and these were presented at an AAC meeting for feedback prior to measure specification. No demographic data were collected to characterize the respondents.

A working group of 5 rheumatologists and health services researchers then prepared the specifications for the final set of measures for development.

Phase 2: Systematic search to support candidate performance measures. A systematic search was conducted to identify existing guidelines and performance measures to ensure the proposed measures were supported by current recommendations, and to harmonize the proposed measure with existing ones (Figure 1; Supplementary Figure 1, available online at jrheum.org).

PubMed and DynaMed electronic databases were searched from 2009 to May 26, 2014 using keywords, synonyms, and MeSH headings for the concepts of IA and Guideline or Indicators (Supplementary Figure 2). A grey literature search was also conducted including rheumatologic society Websites, the National Quality Indicator, and Guidelines Clearing Houses. English language documents from the European continent, Australia, New Zealand, Canada, United States, and the United Kingdom were included. Only guidelines and measures developed and endorsed by a medical society or national healthcare quality regulatory body were included.

The search and preliminary article selection were completed by a medical librarian (Doctor Evidence LLC, a literature review company) based on a predefined protocol. Final article selection was based on relevance to support the measures (conducted by CEHB). This was not a systematic review according to the Preferred Reporting Items for Systematic reviews and Meta-Analyses guidelines ${ }^{14}$. The supporting recommendations were abstracted and included in a background document provided to panelists in Phase 3 .

Phase 3: Online national modified Delphi panel to establish IA performance measures. To ensure wide input, a 3-round, online, modified Delphi panel was conducted using a platform called ExpertLens ${ }^{15,16}$. This platform has previously been used to elicit expert opinion on healthcare topics ${ }^{17,18}$.

For the online panel, 50 people were invited to participate, including rheumatologists, researchers, allied health professionals, government representatives, and people with arthritis. A purposive sampling strategy was used to ensure that all interested groups and all provinces were represented. Individuals were identified by the AAC based on prior involvement in work or activities relevant to measure development. No honoraria or incentives were offered for participation. The University of Calgary Conjoint Research Ethics Board approved the project and RAND's Human Subjects Protection Committee determined that the study was exempt from review.

The panel process took place from September 22 to June 11, 2014, and included 2 rounds of online voting and a discussion round in between. Each round was open for 7-14 days. Periodic reminders were sent to maximize engagement.

In Round 1, panelists were asked to answer a set of 7 questions about each of the 6 candidate measures. They were provided with a background document, which included the rationale and methods for the project, as well as the measure specifications.

Participants were asked to rate the validity and feasibility of candidate measures while considering multiple facets of validity and feasibility $19,20,21$ using a modification of published questions (Table 1). We also asked panelists about the relevance of the measure and the likelihood of use of the measure in their health system.

In Round 2, panelists participated in an asynchronous, anonymized, online discussion. The discussion was moderated by a health services researcher and rheumatologist who had experience with the platform and with the development of the performance measures (CEHB). The moderator asked questions of the panel to clarify responses and to raise discussion of comments submitted anonymously during Round 1 until all concerns raised by participants had been addressed. During this round, panelists also reviewed automatically generated bar graphs showing the distribution of the group's responses. After the discussion round, the core research team made

Personal non-commercial use only. The Journal of Rheumatology Copyright (C) 2016. All rights reserved. 


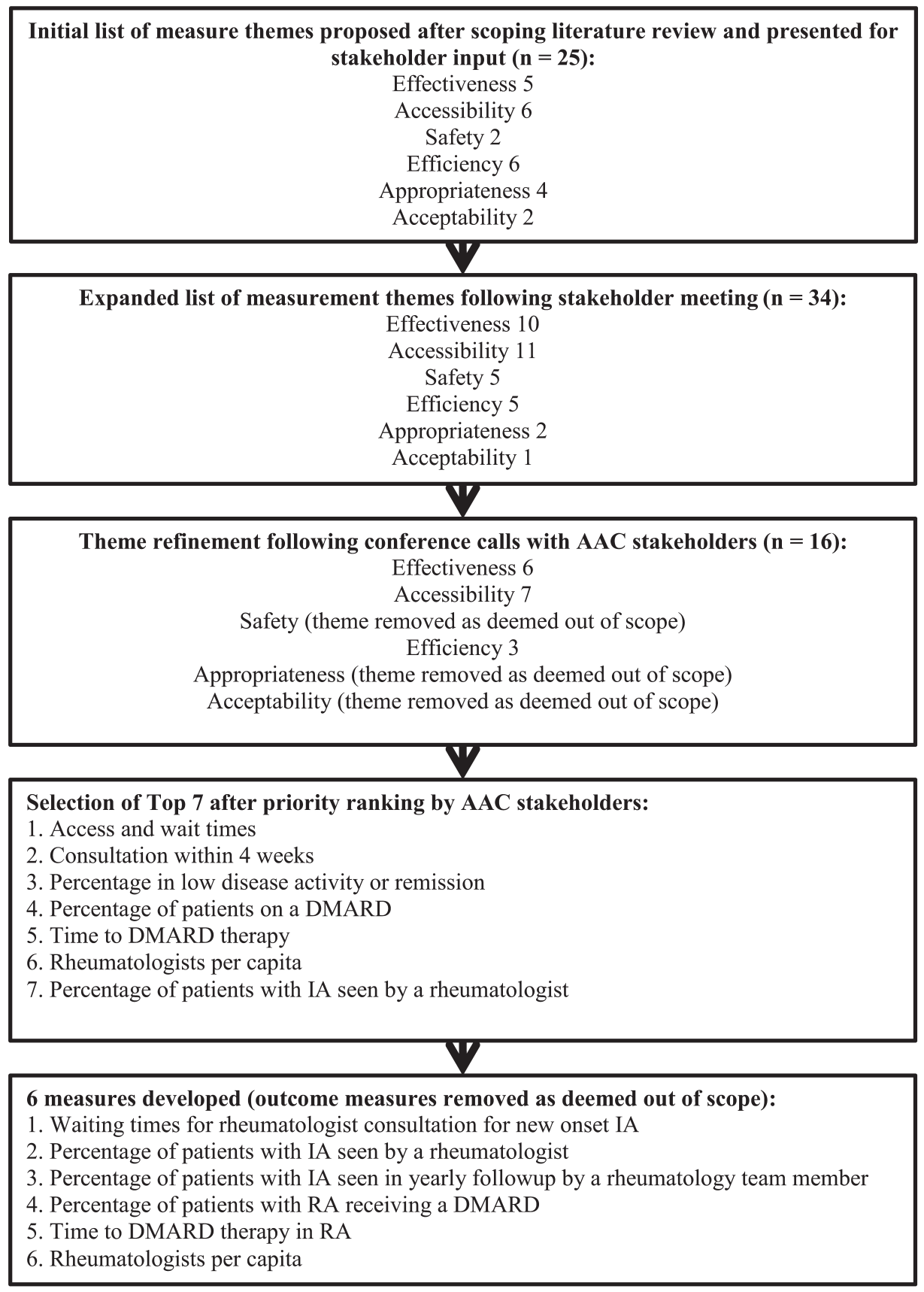

Figure 1. Process for selection of system-level performance measures for IA. IA: inflammatory arthritis; AAC: Arthritis Alliance of Canada; DMARD: disease-modifying antirheumatic drug; RA: rheumatoid arthritis.

a small number of minor changes to the measures to acknowledge the comments made by participants. In Round 3, participants revised their responses to Round 1 questions in light of the Round 2 discussion and feedback.

To be included in the final set, measures had to be rated as valid and relevant (median scores $\geq 7$ on a 9-point scale), with no disagreement. Disagreement was calculated according to the RAND/UCLA Appropriateness Method handbook ${ }^{22}$ : when the Interpercentile Range (IPR; difference between the 30th and 70th percentiles) is larger than the Interpercentile Range Adjusted for Symmetry (IPRAS), which was calcu- lated using the following formula: IPRAS $=2.35+($ Asymmetry Index $[\mathrm{AI}]$ $\times 1.5$ ), where the $\mathrm{AI}$ is the absolute difference between 5 and the central point of the IPR.

Candidate measures with uncertain ratings of data availability or reliability and/or uncertain ratings of whether the health system has control over the measure (i.e., ratings 4-6 on a 9-point scale) were also included in the final set because feasibility of measurement will be tested prior to widespread measure implementation.

Phase 4: AAC comment. The final set of measures was submitted for wide AAC comment. The measures were first presented at a 2-h workshop during 
Table 1. Wording of questions for online Delphi panel to assess validity, feasibility, relevance, and likelihood of use in comparison to previously used panelist questions for quality indicator development.

\begin{tabular}{|c|c|c|}
\hline Variables & Previously Published Panelist Questions ${ }^{19}$ & Questions Modified and Reclassified for the Present Study \\
\hline Validity & $\begin{array}{l}\text { Consider the following*: (1) Is there adequate scientific } \\
\text { evidence or professional consensus to support the indicator? } \\
\text { (2) Are there identifiable health benefits to patients who } \\
\text { receive care specified by the indicator? (3) Based on your } \\
\text { professional experience, would you consider physicians } \\
\text { with significantly higher rates of adherence to the indicator } \\
\text { higher quality providers? (4) Are the majority of factors that } \\
\text { determine adherence to the indicator under the control of the } \\
\text { physician (or are they subject to influence by the physician)? }\end{array}$ & $\begin{array}{l}\text { Scientific support for the candidate measure: How strong is the scientific } \\
\text { evidence or professional consensus supporting this measure? } \\
(1=\text { very weak, } 9 \text { = very strong) } \\
\text { Face validity of the candidate measure: How likely is it that better } \\
\text { performance on the proposed measure indicates a higher quality } \\
\text { health system? ( } 1 \text { = very unlikely, } 9=\text { very likely }) \\
\text { Control over the candidate measure: How well can the factors that } \\
\text { determine performance on this measure be controlled at the } \\
\text { health system level? }(1 \text { = very poorly, } 9=\text { very well })\end{array}$ \\
\hline Feasibility & $\begin{array}{l}\text { Consider the following*: (1) Is the information necessary to } \\
\text { determine adherence possible to find in an average medical } \\
\text { record (or is failure to document such information itself a } \\
\text { marker of poor quality)? (2) Is the estimate of adherence to } \\
\text { the indicator based on medical record data likely to be } \\
\text { reliable and unbiased? }\end{array}$ & $\begin{array}{l}\text { Likelihood of information availability: How likely is it that the } \\
\text { information required to report this measure will be available in a } \\
\text { typical Canadian health system? }(1=\text { very unlikely, } 2 \text { = very likely }) \\
\text { Reliability of the candidate measure: How likely is it that } \\
\text { the measure, calculated based on the available data sources, will } \\
\text { be reliable and unbiased? ( } 1 \text { = very unlikely, } 9=\text { very likely })\end{array}$ \\
\hline Likelihood of Use & N/A & $\begin{array}{l}\text { What is the likelihood that you would use, or encourage the use of, } \\
\text { this measure for quality improvement in your health system? } \\
\text { (1 = very unlikely, } 2 \text { = very likely) }\end{array}$ \\
\hline
\end{tabular}

* Participants are asked to consider all of the questions described and to provide a single overall validity and feasibility rating on a scale of $1-9$, where $1=$ not valid or not feasible and $9=$ definitely valid or definitely feasible. N/A: not applicable.

the Second Annual Conference and Research Symposium in November 2014 and the workshop participants were asked to respond anonymously to the question "How likely would you be to use this measure for quality improvement in your arthritis care system?" using an electronic response system.

The second method for obtaining input was posting the measures on the AAC Website for 1 month and advertising in the AAC newsletter that the document was open for comment.

\section{RESULTS}

Phase 1: Establishing measurement priorities. Following an iterative process of engagement (Figure 1), 16 measurement themes were presented to AAC participants in an online poll to decide which would be most valid, relevant, and feasible to use as performance measures. The top 7 candidate measurement themes were presented at an AAC meeting for additional feedback. The themes included access and waiting times for rheumatologic care (considered broadly in this phase to encompass rheumatologist and/or allied health professional care), consultation for RA within 4 weeks, percentage of patients with RA in low disease activity (LDA) state or remission, percentage of patients with RA receiving a disease-modifying antirheumatic drug (DMARD; Supplementary Material, available online at jrheum.org), time to DMARD therapy (Supplementary Material, available online at jrheum.org), rheumatologists per capita (Supplementary Material, available online at jrheum.org), and percentage of patients with IA seen by a rheumatologist.

During the process, it was determined that the focus of the performance measures should be on the access to rheumatologist care and appropriate treatment, and that the measurement of clinical outcomes was beyond the scope of the project. Therefore, the candidate measure on percentage of patients with RA in LDA or remission was not included. Access to rheumatologist care was prioritized for measure development as opposed to rheumatology care (which encompassed access to other allied health professions) because rheumatologists are the primary specialists responsible for diagnosing and prescribing medication and also because of the concerns about feasibility of measuring access to rheumatology care. The access and waiting time measures were further refined, and standard of consultation within 4 weeks for RA was identified as a benchmark of the waiting time measure (Table 2). Finally, the percentage of patients with IA seen by a rheumatologist was split into 2 measures: 1 identifying the number of patients with newly diagnosed IA and a second identifying the percentage of patients seen in yearly followup (at a minimum to ensure patients were not getting lost to followup; Supplementary Material, available online at jrheum.org). Six measures were selected for further development.

Phase 2: Systematic search to support candidate performance measures. The systematic search identified 1007 articles, and 115 were selected for full-text review (Supplementary Figure 1, available online at jrheum.org). Of these, 26 documents were included that were directly relevant to the candi-

$$
\text { Personal non-commercial use only. The Journal of Rheumatology Copyright } \subset \text { (2016. All rights reserved. }
$$


Table 2. Final set of system level performance measures for IA (complete measure specifications shown in the Supplementary Data, available online at jrheum.org).

\begin{tabular}{ll}
\hline Measures & Descriptions
\end{tabular}

Performance Measure 1: Waiting times for rheumatologist consultation for patients with new onset IA
The number of days that patients waited, between the date the initial referral was received and the date of consultation with a rheumatologist for patients with new onset IA where the diagnosis of IA is made or confirmed by a rheumatologist.

The percentage of patients with new onset IA with at least 1 visit to a rheumatologist in the first year of diagnosis, regardless of who makes the diagnosis.

of patients with IA seen by a rheumatologist

Performance Measure 3: Percentage of patients with IA seen in yearly followup by a rheumatology team member

Performance Measure 4: Percentage of patients with RA treated with a DMARD

Performance Measure 5: Time to DMARD therapy in RA

The percentage of patients with a diagnosis of IA under the care of a rheumatology team seen in followup by a rheumatology team member at least once per year.

The percentage of patients with RA with a DMARD medication prescribed or dispensed during the measurement year.

The number of days between the diagnosis of RA and the time that a DMARD medication was prescribed or dispensed, where the diagnosis of RA was made or confirmed by a rheumatologist.

Performance Measure 6:

Rheumatologists per capita
Primary measure reported: The 50th and 90th percentile waiting times for rheumatologic consultation for each subtype of IA (RA, PsA, AS, JIA)*.

Additional data to be reported: percentage of patients with IA who had a waiting time equal to or shorter than the benchmark waiting times recommended for their specific IA diagnosis based on the WTA (reported for each subtype of IA).

The percentage of patients with new onset IA (incident IA) with at least 1 visit to a rheumatologist in the first year of diagnosis. We propose reporting on this measure for each subtype of IA (RA, PsA, AS, JIA)**.

The percentage of patients with IA seen by their rheumatology team member at least once every year over the measurement period***.

Primary measure reported:

Percentage of patients with RA with a DMARD medication prescribed or dispensed during the measurement year.

Primary measure reported: 50th and 90th percentile times between RA diagnosis and DMARD prescription or dispensing where the diagnosis of RA was made or confirmed by a rheumatologist.

Additional data to be reported: percentage of patients with RA who had a waiting time equal to or shorter than the benchmark waiting times set by the WTA for initiating DMARD treatment.

How many rheumatologists per 100,000 population. Primary measures reported: (1) The number of adult rheumatologists per 100,000 population. (2) The number of FTE adult rheumatologists per 100,000 population. (3) The number of pediatric rheumatologists per 100,000 pediatric population. (4) The number of FTE pediatric rheumatologists per 100,000 pediatric population. Additional data to be reported: (1) Adult rheumatology training programs: Y/N. (2) Pediatric rheumatology training programs: $\mathrm{Y} / \mathrm{N}$

\footnotetext{
* It is not recommended to report an overall wait time for IA given the heterogeneity of disease and targets for wait times. ** It is not recommended to report overall percentages for IA as a combined measure given the heterogeneity of these diseases. Also note that this is not a waiting time measure. This measure will provide an estimate of how many patients with RA are not being seen by a rheumatologist. *** For all types of IA, shorter followup intervals may be highly appropriate and recommended based on disease activity/severity. This measure represents a minimum and will indicate whether patients are getting lost to a minimum level of followup. IA: inflammatory arthritis; RA: rheumatoid arthritis; AS: ankylosing spondylitis; PsA: psoriatic arthritis; JIA: juvenile idiopathic arthritis; WTA: Wait Time Alliance; DMARD: disease-modifying antirheumatic drug; FTE: full-time equivalents; Y/N: Yes/No.
}

date measurement themes: 9 RA guidelines ${ }^{23,24,25,26,27,28,29,30,31}$, 6 RA quality measure documents $32,33,34,35,36,37,4$ PsA guidelines $38,39,40,41,3$ AS guidelines ${ }^{42,43,44}, 1$ AS quality measure document $^{45}, 1$ JIA guideline ${ }^{46}$, and 2 JIA quality measure documents ${ }^{47,48}$. Each guideline recommendation and quality measure was abstracted and included in a document available to panelists in Phase 3. One quality measure developed by the US National Committee on Quality Assurance and endorsed by the American College of Rheumatology 37 and by the National Quality Forum ${ }^{34}$ is used for reporting programs such as the Physician Quality Reporting System ${ }^{33}$ in the United States, and was identified as highly relevant for use in Canada, and measurement specifications were harmonized.

Phase 3: Online national modified Delphi panel to establish IA performance measures. Out of 50 participants invited to participate in the online modified Delphi panel, 42 (84\%) answered at least 1 question in Round 1. However, not all participants answered each question, and the highest number of responses to any question was 42 . In Round 2, 32 participants $(64 \%)$ generated 88 comments. Following Round 2 discussions, minor modifications were made to some 
Table 3. Characteristics of ExpertLens panel participants $(n=43)$. Values are $\mathrm{n}(\%)$ unless otherwise stated.

\begin{tabular}{|c|c|}
\hline Characteristics & Values \\
\hline \multicolumn{2}{|l|}{ Patient characteristics } \\
\hline \multicolumn{2}{|l|}{ Participant background } \\
\hline Physicians & $22(51)$ \\
\hline Allied health professionals & $10(23)$ \\
\hline Person with arthritis & $3(7)$ \\
\hline Researchers & $5(12)$ \\
\hline Other & $2(5)$ \\
\hline No response & $1(2)$ \\
\hline \multicolumn{2}{|l|}{ Province or territory } \\
\hline Alberta & $6(14)$ \\
\hline British Columbia & $6(14)$ \\
\hline Manitoba & $2(5)$ \\
\hline New Brunswick & $1(2)$ \\
\hline Newfoundland and Labrador & $2(5)$ \\
\hline Northwest Territories & $0(0)$ \\
\hline Nova Scotia & $3(7)$ \\
\hline Nunavut & $0(0)$ \\
\hline Ontario & $14(33)$ \\
\hline Prince Edward Island & $0(0)$ \\
\hline Quebec & $6(14)$ \\
\hline Saskatchewan & $2(5)$ \\
\hline Yukon & $0(0)$ \\
\hline No response & $1(2)$ \\
\hline \multicolumn{2}{|l|}{ Urban vs rural location } \\
\hline Urban location & $41(95)$ \\
\hline Rural location & $1(2)$ \\
\hline No response & $1(2)$ \\
\hline \multicolumn{2}{|c|}{ Health professional characteristics, includes physicians and allied health* } \\
\hline \multicolumn{2}{|c|}{ Yrs in practice } \\
\hline$<5$ & 3 \\
\hline $5-10$ & 4 \\
\hline $11-20$ & 12 \\
\hline$>21$ & 15 \\
\hline \multicolumn{2}{|l|}{ Practice setting } \\
\hline Academic: clinical/teaching & 20 \\
\hline Academic: research & 6 \\
\hline Community practice & 7 \\
\hline Other & 1 \\
\hline \multicolumn{2}{|l|}{ Practice patient population } \\
\hline Adult patients with all types of IA & 23 \\
\hline Predominantly RA & 3 \\
\hline Predominantly AS & 1 \\
\hline Predominantly PsA & 0 \\
\hline Predominantly JIA & 5 \\
\hline No. patients with IA routinely seen & 1 \\
\hline Other & 1 \\
\hline
\end{tabular}

* There are 34 respondents in this section; however, only 32 participants indicated they were health professionals in earlier questions. This is because 1 participant did not answer these questions and 3 researchers did (presumably because they are clinician scientists). IA: inflammatory arthritis; RA: rheumatoid arthritis; AS: ankylosing spondylitis; PsA: psoriatic arthritis; JIA: juvenile idiopathic arthritis.

measures. In Round 3, 36 participants provided their final ratings $(72 \%$ of the total invited participants and $86 \%$ of Round 1 participants engaged in Round 3).

A total of 42 participants answered demographic questions and a single participant answered some questions on the performance measures in Round 1, but did not answer demographic questions. Fifty-one percent of respondents were physicians (Table 3). There was participant representation from all Canadian provinces except Prince Edward Island, the Yukon, the North West Territories, and Nunavut.

The results for panel voting are shown in Table 4.

All 6 measures were included in the final set and are shown in Table 2. The full specifications of the measures are provided in the Supplementary Appendix (available online at jrheum.org). The measures focus on the access to rheumatology care and provision of treatment, and cover concepts reported separately for each IA subtype except as indicated. Overall, there was agreement on the validity, relevance, and likelihood of use of the measures (median scores 7-9).

During the discussion round of the online panel, the original wording of \#3 was modified from percentage of patients with IA seen yearly by a rheumatologist to rheumatology team member to reflect the care provided to patients in some models of care, including nurse-led clinics. The same change was not made to \#2 (percentage of patients with IA seen by a rheumatologist) because that measure is intended to reflect incident cases of RA that have not been seen by a rheumatologist for confirmation of diagnosis and treatment.

There was a degree of uncertainty about the feasibility of reporting some of the measures. For example, for \#1 (waiting times for rheumatologist consultation for patients with IA) the median ratings for information availability were 5-6, depending on the subtype of IA. Similarly, there was uncertainty (median scores of 6) about whether reliable and unbiased information was available to report on the following measures: waiting times for rheumatologic consultation for patients with AS and PsA(\#1), the percentage of patients with IA seen by a rheumatologist (\#2), time to DMARD therapy in RA (\#5), and rheumatologists per capita (\#6).

There was also uncertainty over the system's ability to control the performance of 3 of the measures (median scores of 6): the waiting time measure for RA, AS, and PsA (\#1); time to DMARD therapy in RA (\#5); and rheumatologists per capita (\#6).

Two measures (\#1 and \#5) incorporated benchmarks set by the Wait Time Alliance (WTA; a committee that developed the Canadian rheumatology wait time benchmarks $)^{49}$. In Round 3, we asked panelists' opinions of the WTA benchmarks, and they strongly agreed to their inclusion (median 7-8 on a 9-point scale, where 9 is strongly agree).

Phase 4: AAC comment. During the AAC workshop, 34 participants indicated that they were likely or very likely to use the measures for quality improvement in their arthritis care systems (Supplementary Material, available online at jrheum.org).

During roundtable discussions focusing on the feasibility of using the measures and participants' willingness to pilot-test the measures, it was noted that data sources varied

$$
\text { Personal non-commercial use only. The Journal of Rheumatology Copyright } \subset \text { C 2016. All rights reserved. }
$$


Table 4. Results of online modified Delphi panel to develop performance measures for IA (Round 3). Values are median (interquartile range).

Performance Measure 1: Waiting times for rheumatologist consultation for patients with IA

\begin{tabular}{|c|c|c|c|c|}
\hline Variables & RA & AS & PsA & JIA \\
\hline Scientific validity & $8(8-9)$ & $7(5-7)$ & $7(6-8)$ & $7(7-8)$ \\
\hline Face validity & $8(8-9)$ & $8(7-8)$ & $8(8-8)$ & $8(8-9)$ \\
\hline Control over measure & $6(5-7) *$ & $6(5-6)^{*}$ & $6(5-7)^{*}$ & $7(6-7)$ \\
\hline Information reliable and unbiased & $7(6-7)$ & $6(5-7)^{*}$ & $6(6-7)^{*}$ & $7(6-7)$ \\
\hline Relevance & $9(9-9)$ & $8(8-9)$ & $9(8-9)$ & $9(9-9)$ \\
\hline Likelihood of use & $9(8-9)$ & $8(7-9)$ & $8(8-9)$ & $9(8-9)$ \\
\hline Variables & RA & AS & PsA & JIA \\
\hline Scientific validity & $8(7-9)$ & $7(7-8)$ & $8(7-8)$ & $8(8-9)$ \\
\hline Face validity & $8(8-9)$ & $8(8-9)$ & $8(8-9)$ & $8(8-9)$ \\
\hline Control over measure & $7(6-7)$ & $6(6-7)^{*}$ & $7(6-7)$ & $7(6-8)$ \\
\hline Information availability & $7(7-8)$ & $7(6-7)$ & $7(6-7)$ & $7(7-8)$ \\
\hline Information reliable and unbiased & $7(6-8)$ & $6(5-7)^{*}$ & $6(5-7)^{*}$ & $7(6-8)$ \\
\hline Variables & RA & AS & PsA & JIA \\
\hline Scientific validity & $8(7-8)$ & $7(7-8)$ & $7(7-8)$ & $8(7-8)$ \\
\hline Face validity & $8(8-9)$ & $8(7-9)$ & $8(7-9)$ & $9(8-9)$ \\
\hline Control over measure & $7(6-7)$ & $7(6-7)$ & $7(6-8)$ & $7(6-8)$ \\
\hline Information availability & $8(7-8)$ & $7(6-8)$ & $7(6-8)$ & $8(7-8)$ \\
\hline Information reliable and unbiased & $7(6-8)$ & $7(6-8)$ & $7(6-7)$ & $7(6-8)$ \\
\hline Relevance & $9(8-9)$ & $8(7-9)$ & $8(7-9)$ & $8(8-9)$ \\
\hline Likelihood of use & $8(7-9)$ & $8(7-9)$ & $8(7-9)$ & $8(8-9)$ \\
\hline
\end{tabular}

Performance Measure 4: Percentage of patients with RA treated with a DMARD

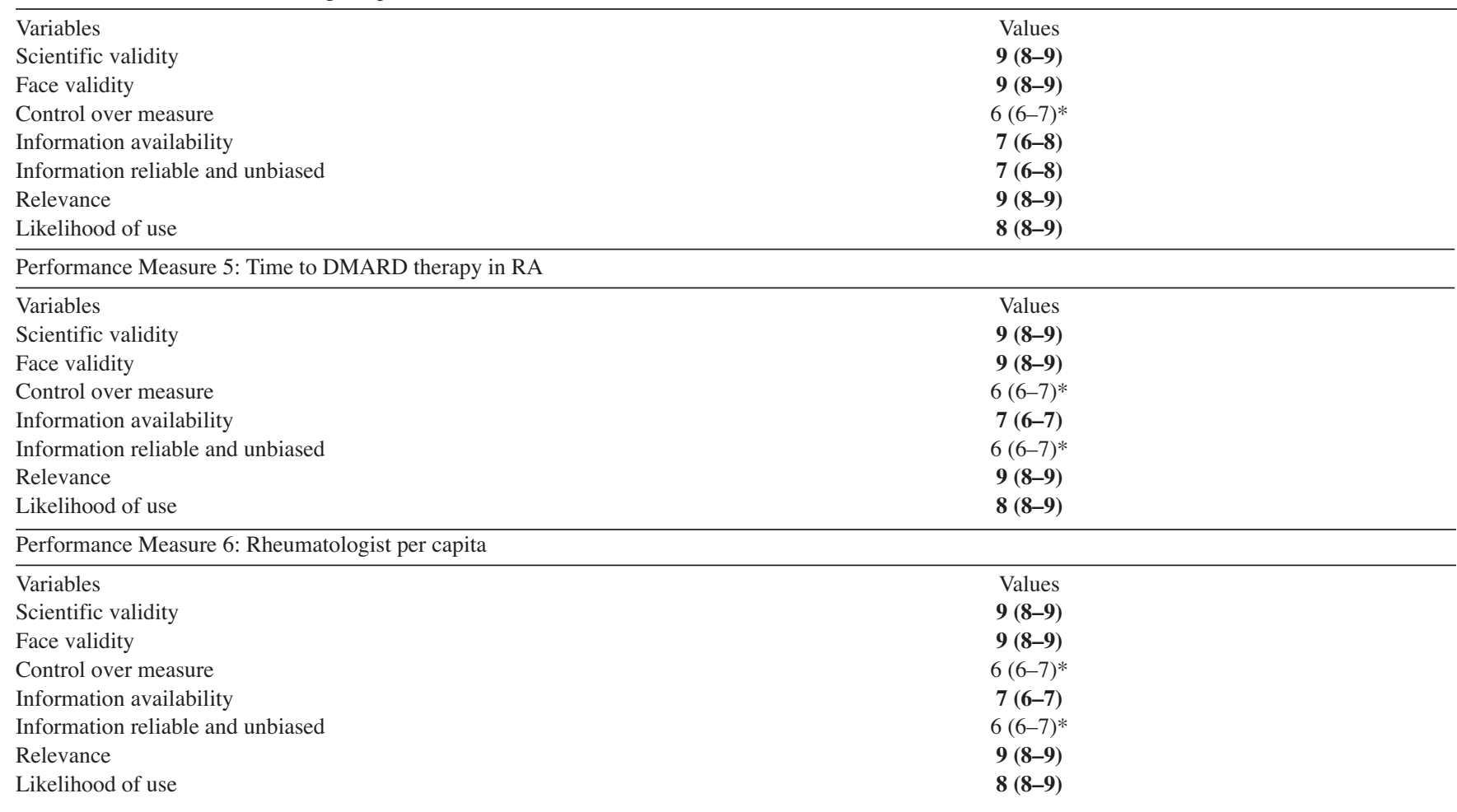

* Ratings 4-6 indicate that the panelists were uncertain as to the validity, relevance, etc. of the candidate measure. Ratings 7-9 in bold face indicate that panelists rated these measures as having high validity, relevance, etc. IA: inflammatory arthritis; RA: rheumatoid arthritis; AS: ankylosing spondylitis; PsA: psoriatic arthritis; JIA: juvenile idiopathic arthritis; DMARD: disease-modifying antirheumatic drug. 
by province/region, which affected the feasibility of implementation. However, some common themes emerged, including the potential use of administrative data, clinical data, registries, and clinical databases for measurement. Overall, there was a high level of enthusiasm for pilot-testing the implementation of the performance measures, but many cited lack of resources or data as potential barriers.

Two comments were provided following the AAC Website posting of the measures. One comment supported the development of the measures, and another suggested some minor clarifications to the specifications, which were incorporated.

\section{DISCUSSION}

To our knowledge, we have developed the first set of system-level performance measures for IA care in Canada through a rigorous methodology involving a multiphase process for varied input. The 6 system-level performance measures address access to specialist care and treatment for people with IA. Reporting on 3 of the measures is further subdivided by type of IA (AS, PsA, RA, JIA), given disease heterogeneity. These performance measures are important for quality improvement and research purposes. The measures can be used in arthritis care settings to examine existing models of care or when evaluating institution of innovations such as central intake systems or alternative models of care delivery, such as telemedicine. While the measures may highlight underserviced regions, this information should not be used for accountability purposes to penalize low resource areas, but should instead help direct resource use and innovations in care delivery to where they are most needed.

The final performance measures developed were deemed valid and relevant by our expert panel and aligned with existing models of care for IA in Canada ${ }^{50}$. While there was some uncertainty about the availability and the reliability of data sources to report on the measures, this varied somewhat according to individual measures and reflects that in many Canadian arthritis centers, high-quality data sources are not currently readily available to measure access to care or adherence to guideline-based treatment. However, a priori we decided not to exclude measures with uncertain feasibility ratings because it was recognized that those domains would need to be tested. We also did not discard measures for which participants indicated uncertainty in the domain of "control over the measure" (How well can the factors that determine performance on this measure be controlled at the health system level?). While in previous measure development studies this concept has been incorporated into assessments of validity, this also relates to feasibility of measure implementation and will be evaluated during testing. To our knowledge, ours is the first study separating validity and feasibility questions to test 1 concept per question. This yielded valuable information, reflecting the nuances of the participants' perceptions in these domains.

Strengths of our methodology include the use of an online modified Delphi panel platform to explore opinions about the performance measures because it allowed us to gain input from a wide variety of geographically dispersed stakeholders. Typical panels for performance measure development often use a smaller in-person meeting for Round 2 and traditionally have included only clinicians and researchers ${ }^{22}$. Additionally, our panel response rates were high (86\% in Round 1 and $72 \%$ in Round 3) and compared favorably with other online modified Delphi panels run on this platform ${ }^{21}$. Another strength of our study was wide input at all development stages to identify measurement priorities and to comment on the measurement specifications. The participants represented arthritis care settings and models of care from across Canada, including academic and community practices. Recruiting participants from rural regions was challenging. Consequently, only 1 participant was from a rural area. This likely reflects the geographic distribution of arthritis health professionals, who cluster in urban centers. Inclusion of 7 healthcare professionals from community practice favorably affects the generalizability of our findings. We also had arthritis patient input through engagement at AAC meetings (Phases 1 and 4) as well as participation in the ExpertLens panel (Phase 3).

A limitation of our work is that we were not able to develop all measurement themes presented during the initial discussions. During the measure development phase of the project, access to care and guideline-based treatment were prioritized because understanding access is critical before evaluating outcomes. Additionally, because of the heterogeneity of diseases encompassed by the term $I A$, it was not feasible to develop performance measures for reporting on guideline-based treatment for IA subtypes beyond RA. Appropriate guideline-based treatment for AS, PsA, and JIA is closely tied to monitoring disease activity, and measurement of outcomes was beyond the project scope. Also, although a systematic search was used to define our evidence base for measure development, it was not a formal systematic review and it is possible some relevant recommendations or measures were missed.

An additional limitation is the possibility of some overlap of respondents between Phase 3 and Phase 4; however, the degree of overlap is unknown because the participants in Phase 3 were anonymous. We were also not able to characterize the respondents during the online poll in Phase 1 because no demographic data were collected, which may be a limitation in describing whether these individuals had the requisite knowledge for this measure development stage. Finally, it is possible that a responder bias could have influenced the results of our measure development or our AAC comment period because it is likely that the most invested and enthusiastic members participated in this work.

We anticipate that some of the measures will be identified in administrative health data, while others may be best reported using clinic databases or clinical registries. We

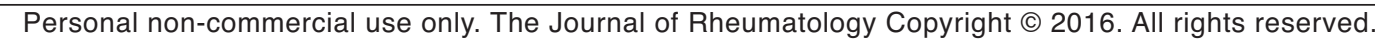


caution, however, that measures identified using different data sources may vary in important ways because of the differences in the population being studied or the type of data available and therefore may not always be comparable. For example, for Performance Measure 4 (percentage of patients with RA treated with a DMARD), clinic data identified DMARD prescribed whereas claims data identified DMARD dispensed.

Further work on harmonizing data collection across arthritis care settings for reporting on these measures is ongoing at a national level through related projects at the AAC. Additionally, an expansion of the measurement framework is planned, including measures encompassing best practices for management of IA, provision of patient information on self-management, and access to arthritis resources.

We have developed a set of system-level performance measures for IA care. The measures were developed in a Canadian setting, but both our process and findings are relevant to other arthritis care settings. The measures focus on access to specialist care and provision of guideline-based treatment, and are reported for each subtype of IA. The measures were rigorously developed and will be tested in arthritis care settings for feasibility of implementation. The measures are a critical starting point for evaluating access to arthritis care and for use in quality improvement.

\section{ACKNOWLEDGMENT}

Jaime Coish is the executive director of the Arthritis Alliance of Canada (AAC) and facilitated administrative support, meeting organization, and participant engagement in this project. Lina Gazizova is a project manager for the AAC and provided administrative and meeting support for this project and helped facilitate participant communication and engagement in this project. Jonathan Riley contributed to the writing of the Canadian Institutes for Health Research planning grant, which helped fund this project. Jenny Wang contributed to the organization and the literature review for the first meeting of interested parties in Phase 1 of this project described in Supplementary Figure 2 (available online at jrheum.org). Samra Mian contributed to the preparation of slide decks for meetings in Phase 1 of this project and conducted literature searches to supplement background information for the project.

\section{ONLINE SUPPLEMENT}

Supplementary data for this article are available online at jrheum.org.

\section{APPENDIX 1.}

List of study collaborators. Members of the Arthritis Alliance of Canada Performance Measurement Development Panel: Vandana Ahluwalia, MD, FRCPC, Corporate Chief of Rheumatology, William Osler Health System; Henry Averns, MB, ChB, FRCP (UK), FRCPC, Rheumatologist; Cheryl Barnabe, MD, FRCPC, MSc, Assistant Professor, Division of Rheumatology, Department of Medicine, Department of Community Health Sciences, University of Calgary, ARC Research Scientist; Claire Bombardier, MD, MSc, FRCPC, Professor of Medicine, Rheumatology Division Director, University of Toronto, Senior Scientist, Institute for Work and Health; Susan J. Bartlett, PhD, Association Professor, Divisions of Clinical Epidemiology, Rheumatology and Respirology, McGill University/MUHC; Sasha Bernatsky, MD, FRCPC, PhD, Associate Professor, Divisions of Rheumatology and Clinical Epidemiology, McGill University; Jennifer Burt,
PT, Rheumatology Services, St. Clare's Mercy Hospital, Eastern Health; Debbie Feldman, PT, PhD, Professor of Medicine, School of Rehabilitation, Université de Montréal; Dafna D. Gladman, MD, FRCPC, Professor of Medicine, University of Toronto, Division of Rheumatology, Senior Scientist, Toronto Western Research Institute; Beverly Greene, RN, MN, Director Chronic Disease Prevention Unit, New Brunswick Department of Health; Boulos Haraoui, MD, FRCPC, Associate Professor, Division of Rheumatology, Department of Medicine, University of Montreal; Nigil Haroon, MD, PhD, DM, Assistant Professor, Division of Rheumatology, Department of Medicine University of Toronto; Catherine Hofstetter, Patient, Canadian Arthritis Patient Alliance; Adam M. Huber, MSc, MD, IWK Health Centre and Dalhousie University; Stephanie Keeling, MD, FRCPC, MSc, Associate Professor, Division of Rheumatology, Department of Medicine, University of Alberta; Bianca Lang, MD, FRCPC, Professor, Division of Rheumatology, Department of Pediatrics, Dalhousie University, Head Division of Rheumatology, IWK Health Centre; Sharon A. Le Clercq, MD, FRCPC, Associate Clinical Professor, Division of Rheumatology, Department of Medicine, University of Calgary; Theresa Lupton, RN, CCRP, Nurse Clinician Rheumatology, Alberta Health Services; Anne Lyddiatt, Patient; Rashmi Mandhane, BScPT, Alberta Health Services; Kimberly Morishita, MD, MHSc, FRCPC, Clinical Assistant Professor, Division of Rheumatology, Department of Pediatrics, University of British Columbia, Pediatrician, BC Children's Hospital; Angelo Papachristos, BSc, BScPT, MBA, ACPAC, Advance Practice Physiotherapist, St. Michael's Hospital, Clinical Lecturer University of Toronto; Patricia Patrick, BsN, RN, Nurse, Clinician Rheumatology; Dawn Richards, PhD, person who lives with rheumatoid arthritis, Vice President, Canadian Arthritis Patient Alliance; David Robinson, MD, MSc, FRCPC, Associate Professor of Medicine, University of Manitoba; Natalie J. Shiff, MD, FRCPC, MHSc, Assistant Professor, Division of Rheumatology, Department of Pediatrics, University of Saskatchewan; Trudy Taylor, MD, FRCPC, Assistant Professor, Department of Medicine, Division of Rheumatology, Division of Medical Education, Dalhousie University; Regina Taylor-Gjevre, MD, FRCPC, MSc, Professor, Division of Rheumatology, Department of Medicine, University of Saskatchewan; Glen T.D. Thomson, MD, FRCPC Rheumatologist; Carter Thorne, MD, Director, The Arthritis Program Southlake Regional Health Centre, Assistant Professor Department of Med, Division of Rheumatology, University of Toronto; Karine Toupin-April, PhD, Associate Scientist, Children's Hospital of Eastern Ontario Research Institute, Assistant Professor, Department of Pediatrics, Faculty of Medicine, University of Ottawa; Peter Tugwell, MD, FRCPC, Cochrane Collaboration Musculoskeletal Review Group, Department of Medicine, University of Ottawa; Marie D. Westby, PT, PhD, Physical Therapy Teaching Supervisor, Mary Pack Arthritis Program, Vancouver Coastal Health; Jessica Widdifield, $\mathrm{PhD}$, McGill University; Linda Woodhouse, PT, PhD, Associate Professor and David Magee Endowed Chair in Physical Therapy, University of Alberta, Scientific Director, Alberta Health Services Bone and Joint Health Strategic Clinical Network; Michel Zummer, MD, FRCPC, Chief, Rheumatology, Hôpital Maisonneuve-Rosemont, Associate Professor, Université de Montréal.

\section{REFERENCES}

1. Ahluwalia V, Frank C, Mosher DP, Zummer M. A pan-Canadian approach to inflammatory arthritis models of care. [Internet. Accessed November 17, 2015.] Available from: www.arthritisalliance.ca

2. Bosello S, Fedele AL, Peluso G, Gremese E, Tolusso B, Ferraccioli G. Very early rheumatoid arthritis is the major predictor of major outcomes: clinical ACR remission and radiographic non-progression. Ann Rheum Dis 2011;70:1292-5.

3. Nell VP, Machold KP, Eberl G, Stamm TA, Uffmann M, Smolen JS. Benefit of very early referral and very early therapy with disease-modifying anti-rheumatic drugs in patients with early rheumatoid arthritis. Rheumatology 2004;43:906-14.

4. Kirkham B, Li W, Boggs R, Nab R, Tarallo M. Early treatment of

Personal non-commercial use only. The Journal of Rheumatology Copyright @ $\odot$ 2016. All rights reserved 
psoriatic arthritis is associated with improved outcomes: findings from the Etanercept (Enbrel) PRESTA Trial. Arthritis Rheum 2011;63 Suppl 10:1288.

5. Haroon M, Gallagher P, FitzGerald O. Diagnostic delay of more than 6 months contributes to poor radiographic and functional outcome in psoriatic arthritis. Ann Rheum Dis 2015;74:1045-50.

6. Wallace CA, Giannini EH, Spalding SJ, Hashkes PJ, O’Neil KM, Zeft AS, et al; Childhood Arthritis and Rheumatology Research Alliance. Trial of early aggressive therapy in polyarticular juvenile idiopathic arthritis. Arthritis Rheum 2012;64:2012-21.

7. Widdifield J, Paterson JM, Bernatsky S, Tu K, Thorne JC, Ahluwalia V, et al. The rising burden of rheumatoid arthritis surpasses rheumatology supply in Ontario. Can J Public Health 2013;104:e450-5.

8. Kur J, Koehler B. Rheumatologist demographics in British Columbia: a looming crisis. BCMJ 2011;53:128-31.

9. Chan J, Kur J. Update on rheumatologist demographics in British Columbia. CRAJ 2014;24:15.

10. Widdifield J, Bernatsky S, Paterson JM, Thorne JC, Cividino A, Pope J, et al. Quality care in seniors with new-onset rheumatoid arthritis: a Canadian perspective. Arthritis Care Res 2011;63:53-7.

11. Speerin R, Slater H, Li L, Moore K, Chan M, Dreinhöfer K, et al. Moving from evidence to practice: models of care for the prevention and management of musculoskeletal conditions. Best Pract Res Clin Rheumatol 2014;28:479-515.

12. Arthritis Alliance of Canada. Arthritis Alliance of Canada. [Internet. Accessed November 17, 2015.] Available from: arthritisalliance.ca/en

13. Health Quality Council of Alberta. The Alberta quality matrix for health. [Internet. Accessed November 17, 2015.] Available from: hqca.ca/about/how-we-work/the-alberta-quality-matrix-for-health-1/

14. PRISMA. Transparent reporting of systematic reviews and meta-analyses. [Internet. Accessed November 17, 2015.] Available from: www.prisma-statement.org

15. Dalal S, Khodyakov D, Srinivasan R, Straus SG, Adams JL. ExpertLens: a system for eliciting opinions from a large pool of non-collocated experts with diverse knowledge. Technol Forecast Soc 2011;78:1426-44

16. Khodyakov D, Hempel S, Rubenstein L, Shekelle P, Foy R, Salem-Schatz $\mathrm{S}$, et al. Conducting online expert panels: a feasibility and experimental replicability study. BMC Med Res Methodol 2011;11:174.

17. Rubenstein L, Khodyakov D, Hempel S, Danz M, Salem-Schatz S, Foy R, et al. How can we recognize continuous quality improvement? Int J Qual Health Care 2014;26:6-15.

18. Claassen CA, Pearson JL, Khodyakov D, Satow PM, Gebbia R, Berman AL, et al. Reducing the burden of suicide in the U.S.: the aspirational research goals of the National Action Alliance for Suicide Prevention Research Prioritization Task Force. Am J Prev Med 2014;47:309-14.

19. Yazdany J, Panopalis P, Gillis JZ, Schmajuk G, MacLean CH, Wofsy D, et al; Systemic Lupus Erythematosus Quality Indicators Project Expert Panels. A quality indicator set for systemic lupus erythematosus. Arthritis Rheum 2009;61:370-7.

20. Mangione-Smith R, DeCristofaro AH, Setodji CM, Keesey J, Klein DJ, Adams JL, et al. The quality of ambulatory care delivered to children in the United States. N Engl J Med 2007;357:1515-23.

21. Barber CE, Marshall DA, Alvarez N, Mancini GB, Lacaille D, Keeling S, et al. Development of cardiovascular quality indicators for rheumatoid arthritis: results from an international expert panel using a novel online process. J Rheumatol 2015;42:1548-55.

22. Fitch K, Bernstein SJ, Aguilar MD, Burnand B, LaCalle JR, Lazaro $\mathrm{P}$, et al. The RAND/UCLA appropriateness method user's manual. [Internet. Accessed November 17, 2015.] Available from: www.rand.org/pubs/monograph_reports/MR1269.html
23. Albrecht K, Kruger K, Wollenhaupt J, Alten R, Backhaus M, Baerwald C, et al; German Society of Rheumatology. German guidelines for the sequential medical treatment of rheumatoid arthritis with traditional and biologic disease-modifying antirheumatic drugs. Rheumatol Int 2014;34:1-9.

24. Bykerk VP, Akhavan P, Hazlewood GS, Schieir O, Dooley A, Haraoui B, et al; Canadian Rheumatology Association. Canadian Rheumatology Association recommendations for pharmacological management of rheumatoid arthritis with traditional and biologic disease-modifying antirheumatic drugs. J Rheumatol 2012; 39:1559-82.

25. Luqmani R, Hennell S, Estrach C, Basher D, Birrell F, Bosworth A, et al; British Society for Rheumatology; British Health Professionals in Rheumatology Standards, Guidelines and Audit Working Group. British Society for Rheumatology and British Health Professionals in Rheumatology guideline for the management of rheumatoid arthritis (after the first 2 years). Rheumatology 2009;48:436-9.

26. National Institute for Health and Clinical Excellence. Rheumatoid arthritis in adults: management. [Internet. Accessed November 17, 2015.] Available from: www.nice.org.uk/guidance/cg79

27. Scottish Intercollegiate Guidelines Network (SIGN). Management of early rheumatoid arthritis: a national clinical guideline. [Internet. Accessed November 17, 2015.] Available from: www.sign.ac.uk/guidelines/fulltext/123/index.html

28. Singh JA, Furst DE, Bharat A, Curtis JR, Kavanaugh AF, Kremer JM, et al. 2012 update of the 2008 American College of Rheumatology recommendations for the use of disease-modifying antirheumatic drugs and biologic agents in the treatment of rheumatoid arthritis. Arthritis Care Res 2012;64:625-39.

29. Smolen JS, Landewé R, Breedveld FC, Buch M, Burmester G, Dougados $\mathrm{M}$, et al. EULAR recommendations for the management of rheumatoid arthritis with synthetic and biological disease-modifying antirheumatic drugs: 2013 update. Ann Rheum Dis 2014;73:492-509.

30. Spanish Society of Rheumatology (SER). Update of the clinical practice guideline for the management of rheumatoid arthritis in Spain. [Internet. Accessed November 18, 2015.] Available from: www.ser.es/guipcar

31. The Royal Australian College of General Practitioners (RACGP). Clinical guideline for the diagnosis and management of early rheumatoid arthritis. [Internet. Accessed November 17, 2015.] Available from: www.racgp.org.au/download/documents/ Guidelines/Musculoskeletal/racgp_ra_guideline.pdf

32. British Medical Association (BMA) and NHS Employers. Rheumatoid arthritis: the percentage of patients with rheumatoid arthritis, on the register, who have had a face-to-face review in the preceding 12 months. [Internet. Accessed November 17, 2015.] Available from: www.qualitymeasures.ahrq.gov/ content.aspx . id=45469

33. Centers for Medicare and Medicaid Services. 2014 Physician Quality Reporting System (PQRS) measures specifications manual for claims and registry reporting of individual measures. [Internet. Accessed November 17, 2015.] Available from: www.google.ca/url? sa $=t \& r c t=j \& q=\&$ esrc $=s \&$ source $=$ web $\& c d=3 \& v$ ed=0CC0QFjAC\&url=http $\% 3 \mathrm{~A} \% 2 \mathrm{~F} \% 2 \mathrm{Fwww}$.entnet.org $\% 2 \mathrm{Fsites}$ $\% 2$ Fdefault $\% 2$ Ffiles $\% 2$ FPQRS-Measures-Spec-Manual_ Individuall_Measures_0.pdf\&ei=TFEUVeGLAtCsyASr54CQAg\&u sg=AFQjCNFzpjDnw4XZ00Zex5nVFqwsIAhmXg\&bvm=bv.8938 1419,d.aWw

34. National Committee for Quality Assurance. Disease modifying anti-rheumatic drug therapy for rheumatoid arthritis. [Internet. Accessed November 17, 2015.] Available from: www.qualityforum.org

35. National Institute for Health Care Excellence (NICE). Quality

Personal non-commercial use only. The Journal of Rheumatology Copyright (C) 2016. All rights reserved. 
standard for rheumatoid arthritis (QS33). [Internet. Accessed November 17, 2015.] Available from: publications.nice.org.uk/ quality-standard-for-rheumatoid-arthritis-qs33

36. Petersson IF, Strombeck B, Andersen L, Cimmino M, Greiff R, Loza E, et al; eumusc.net-working group. Development of healthcare quality indicators for rheumatoid arthritis in Europe: the eumusc.net project. Ann Rheum Dis 2014;73:906-8.

37. American College of Rheumatology. Rheumatoid arthritis quality indicators. [Internet. Accessed November 17, 2015.] Available from: www.rheumatology.org/Practice-Quality/Clinical-Support/ Quality-Measurement/ACR-Endorsed-Measures

38. Dernis E, Lavie F, Salliot C, Flipo RM, Saraux A, Maillefert JF, et al. Pharmacological treatment (biotherapy excluded) of peripheral psoriatic arthritis: development of recommendations for clinical practice based on data from the literature and experts opinion. Joint Bone Spine 2009;76:524-31.

39. Gossec L, Smolen JS, Gaujoux-Viala C, Ash Z, Marzo-Ortega H, van der Heijde D, et al; European League Against Rheumatism. European League Against Rheumatism recommendations for the management of psoriatic arthritis with pharmacological therapies. Ann Rheum Dis 2012;71:4-12.

40. Ritchlin CT, Kavanaugh A, Gladman DD, Mease PJ, Helliwell P, Boehncke WH, et al; Group for Research and Assessment of Psoriasis and Psoriatic Arthritis (GRAPPA). Treatment recommendations for psoriatic arthritis. Ann Rheum Dis 2009;68:1387-94.

41. Scottish Intercollegiate Guidelines Network. Diagnosis and management of psoriasis and psoriatic arthritis in adults. A national clinical guideline. [Internet. Accessed November 17, 2015.] Available from: sign.ac.uk/guidelines/fulltext/121/index.html

42. Braun J, van den Berg R, Baraliakos X, Boehm H, Burgos-Vargas R, Collantes-Estevez E, et al. 2010 update of the ASAS/EULAR recommendations for the management of ankylosing spondylitis. Ann Rheum Dis 2011;70:896-904.
43. Agency for Healthcare Research and Quality. Espoguia (clinical guidelines for patients with spondyloarthritis). [Internet. Accessed November 17, 2015.] Available from: www.guideline.gov/content.aspx?id=33577\&search=arthritis

44. Wendling D, Lukas C, Paccou J, Claudepierre P, Carton L, Combe B, et al. Recommendations of the French Society for Rheumatology (SFR) on the everyday management of patients with spondyloarthritis. Joint Bone Spine 2014;81:6-14.

45. Abad MÁ, Ariza RA, Aznar JJ, Batlle E, Beltrán E, de Dios Cañete $\mathrm{J}$, et al. Standards of care for patients with spondyloarthritis. Rheumatol Int 2014;34:165-70.

46. The Royal Australian College of General Practitioners (RACGP). Clinical guideline for the diagnosis and management of juvenile idiopathic arthritis. [Internet. Accessed November 17, 2015.] Available from: www.nhmrc.gov.au/guidelines/publications/cp119

47. Davies K, Cleary G, Foster H, Hutchinson E, Baildam E; British Society of Paediatric and Adolescent Rheumatology. BSPAR Standards of Care for children and young people with juvenile idiopathic arthritis. Rheumatology 2010;49:1406-8.

48. Lovell DJ, Passo MH, Beukelman T, Bowyer SL, Gottlieb BS, Henrickson M, et al. Measuring process of arthritis care: a proposed set of quality measures for the process of care in juvenile idiopathic arthritis. Arthritis Care Res 2011;63:10-6.

49. Canadian Rheumatology Association. Wait time benchmarks for arthritis care. [Internet. Accessed December 17, 2015.] Available from: www.waittimealliance.ca/benchmarks/arthritis-care/

50. Li LC, Badley EM, MacKay C, Mosher D, Jamal SW, Jones A, et al. An evidence-informed, integrated framework for rheumatoid arthritis care. Arthritis Rheum 2008;59:1171-83. 